\title{
Pasiones barrocas
}

\author{
BLAS MATAMORO
}

\author{
«... un hombre puede producir a otro hombre pero no \\ una homiga; y un rey, que se hace obedecer por todo un \\ pueblo, a veces no logra ser obedecido por un caballos (Des- \\ cartes al padre Mesland, 2-V-1644).
}

No es infundado situar en el barroco el comienzo de la moderna psicología. En primer lugar, por un perfilado intento, de origen moralizante, de clasificar las pasiones y, a partir de ellas, trazar tipos psicológicos (La Bruyère, La Rochefoucauld). Luego, porque el ensayo, descartado, de constituir una lengua universal admite la inexistencia de una clave lingüística definitiva, a la vez que constituye todo el lenguaje como un juego metafórico, con una lógica intrinscca que se organiza y a la vez se oculta on la metáfora. Este desfase entre pensamiento y palabra, entre el decir y lo dicho, produce un nuevo objeto psicológico, que no es pensamiento ni palabra, sino pensamiento de la palabra. Lo explica Descartes en Los principios de la filosofia $(I, 74)$ : «... adjuntamos a nuestros pensamientos unas palabras que no los expresan exactamente». La inexactitud verbal hace que todo el mundo sea incierto y dudoso. La única certeza indudable es el yo que piensa, y sólo en tanto piensa, o sea: el discurso que se toma a sí mismo como objeto y no depende de las inseguras referencias externas. De algún modo, en el teatro calderoniano se ponen en escena estas antítesis entre la apariencia y el ser, entre un mundo engañoso e ilusorio, cuya consistencia es onirica, y una realidad oculta pero que es, para el alma, lo único real y consistente.

Pero, sobre todo, la psicología moderna halla su marca inicial en el barroco por el tratamiento que sus grandes metafísicos (en cl caso, Descartes y Spinoza) dan al conflicto tradicional entre la razón y las pasiones. Hasta entonces, las salidas que los filósofos proponian al mencionado conflicto, mantenian la calidad de los oponentes, en una suerte de pacto de no beligerancia. Aristótcles y la cscolástica aconsejaban el justo medio: el hombre no debe ser exclusivamente racional ni pasional, sino una suma equilibrada de ambos componentes. Los estoicos, Séneca en particular, aconsejaban domesticar las pasiones, calmándolas, volviéndolas un servil animal casero, con el cual se puede convivir razonablemente. En especial, la preocupación estoica, que llega hasta Montaigne, es la libertad que nace de neutralizar las dos grandes pasiones: la negativa (el temor) y la positiva (la esperanza), pues ambas son chantajes que nos hace la muerte para detener por parálisis nuestra vida moral, Es libre, para el estoico, el hombre que no teme a la muerte ni espera nada de ella.

En el barroco, tan cercano al relativo estoicismo de Montaigne, el tema se resuelve en favor de la pasión como afirmación de la vida y alejamiento de la muerte (de nuevo Descartes y Spinoza) o no se resuelve y se declara trágico, como en Pascal, porque la solución está en el seno de Dios, cse Dios inabordable, oculto $y$ ausente de su obra maestra, cuyas divinas decisiones siempre son innaccesibles al hombre. 


\section{I}

Descartes se dedica tardíamente al asunto de to que hoy llamariamos afectividad (Tratado de las pasiones, 1649), por sugerencia de una mujer bella, de cara infantil y resabia, inteligente, obviamente noble y curiosa, una femme savante de aquéllas: la princesa Isabel de Bohemia. Lo traigo a colación porque a más de un moralista contemporáneo le hubiera parecido, cuando menos, obsceno, y cuando más, inútil, hablar de pasiones a una señora.

La pasión cartesiana es el punto de encuentro del cuerpo y el alma, una acción en la que el cuerpo influye sobre el alma. El cuerpo mueve al alma y viceversa, de modo que el cuerpo gesticula, sufre alteraciones, etc., poniendo en movimiento un código gestual y fisiológico de la pasión. El cuerpo se anima, tanto como el alma se corporiza, se encarna en ese tercer mundo de la pasión. Dice Descartes: «... hay tal vínculo entre nuestra alma y nuestro cuerpo, que en cuanto hemos unido una acción corporal a un pensamiento, la una no se presenta nunca sin el otro». En distinta dirección: el alma es el principio de unidad, identidad y duración del cuerpo. Es decir: si bien el cuerpo es materia extensa, no es mera opacidad, sino que resulta productor de sentido, capaz de cierta articulación (inteligir lo que puede imaginar) lo mismo que está ya articulado por naturaleza, organizado por definición. Es cierto que, además, el alma puede tener acciones "propiamente dichas", que son las ejercidas sobre sí misma por ella misma, que es cuando puede inteligir lo que no puede imaginar (ejemplo: considerar su propia naturaleza), hacer metafísica.

Entonces: la pasión, nacida del cuerpo, es un suceso moral y epistemológico cn sí misma. Las pasiones «son todas buenas en su naturalezas. Hay un saber de las pasiones que lleva a conocer la regla que las modera, convirtiéndolas en instrumento de la razón, que no podría mediatizarlas si ellas no tuvieran algo racional que ofrecerle. No son conocimiento pero son sagesse, sapiencia, sabiduría fundante. Por ello, los mejores espíritus son los que tienen pasiones más violentas, que actúan más fuertemente sobre su cuerpo. Si se tiene buen sentido, no hay mal del que no se pueda obtener algún provecho moral. La filosofia, en estos casos, sirve para extraer la dicha del interior (bonheur), sin esperarla del exterior, como obra de la Fortuna (heur).

Algo similar discurre Spinoza en su Ética (publicada póstuma en 1677). Los afectos spinocianos resultan de un aumento en la potencia de obrar del cuerpo, de modo que producen sus propias ideas (III, «Definiciones"). Dentro de ellos, las pasiones nos tienen por causa parcial. Si la causa es adecuada a un fin, la pasión se torna acción. Es decir, que no hay acción sin pasión. También, como en Descartes, la pasión se instala en la sutura cuerpo/alma, que para Spinoza son una cosa misma con un doble juego de causalidades, discontinuas y sin influencia mutua: lo pensante y lo extenso. Pero, en cualquier caso, en la pasión ya hay un nivel del saber: la pasión no es ciega sino que posee algún tipo de discernimiento: «Un afecto que se dice pasión del ánimo, es una idea confusa por la cual el alma afirma de su cuerpo o de alguna de sus partes una fuerza de existir mayor o menor que antes y por la cual, una vez dada la idea, el alma misma es determinada a pensar tal cosa más bien que tal otra» (Ética, III, XLVIII).

En el barroco ya se cuenta, según se va viendo, con ese vínculo entre sentimiento y saber, que será elaborado por Malebranche, la escuela alemana de la Empfindsamkeit y el romanticismo. Sentir es recorrer el camino más breve hacia un saber que no puede proporcionarnos ninguna ciencia (inexistente, imposible). Así, la alegría lleva a conocer lo bueno y la tristeza, lo malo (Spinoza: Ética, IV, VIII). Las pasiones no son ya los enemigos del 
alma, sino sus auxiliares afectivos, o su obstáculo dialéctico, imprescindible para su formación moral. Tampoco son una mera cantidad desdeñable de materia extensa, que se interpone en el camino hacia la luminosa distinción entre las virtudes y los vicios. Las pasiones son un episodio en la historia moral del alma.

Algo similar se puede advertir en el deseo, personaje vapuleado, más tarde, por la ética clásica, como querer de to imposible, opuesto a la voluntad, querer de lo posible y única volición posible de consideración moral. El deseo cartesiano, en cambio, es siempre la perpetuación del bien o la evitación del mal, y se relaciona con el porvenir, o sea con la historia del sujeto moral: el futuro es, precisamente, lo deseable. El bien querido es un objeto ético, es una meta, y el deseo es capaz de distinguirlo. Lo malo del deseo es que no se someta al objeto reconocido o, como dice Descartes: «... es evidente que en tanto procede de un verdadero conocimiento, no puede ser malo, en cuanto no se exceda $y$ dicho conocimiento lo regule». Aun cuando se funde en un error, el desco lleva en si mismo su criterio de corrección.

En un sentido cognoscitivo, el deseo es también agente del saber. No se desea sino lo que, de alguna manera, se juzga posible. La sapiencia deseante sabe que va a ocurrir lo que se produzca conforme a lo ya ocurrido, qué tal es lo que denominamos posible, lo sometido, según el vocabulario heredado del Renacimiento, a «la ley de la Fortuna». Este acuerdo entre el deseo y cierta legalidad del mundo permite al sujeto discernir lo posible de lo imposible y evitar la fatalidad, que es lo necesario, puro y absoluto.

Cuando la cosa acaecida se conforma con la espcrada, nace la alegría, que es la cartesiana conformidad con el deber (de nuevo, la alegría es positivamente moral): las cosas ocurren como deben ocurrir. Esta adquisición del bien satisface íntimamente al sujeto que lo obtiene. No es el reco- nocimiento de un tercero, ni la fama ni la gloria, lo que corrobora la bondad del bien logrado, sino una actitud de la naturaleza ética alojada en la intimidad de cada hombre. Su contrafaz (del deseo, quiero decir) son los celos, el temor a perder el bien adquirido.

Spínoza va más lejos que su colega: «El deseo es la esencia misma del hombre en cuanto es concebida como determinada a obrar algo por una afección cualquiera dada en ella» (Ética, III, LIX). Es decir, que el hombre se define como ser deseante. Esta calidad, a su vez, se funda en un afecto primitivo anterior, que es el sentimiento de la perfección, de la plenitud. Ante la expectativa de conseguirse, produce alegría y, de lo contrario, tristeza. La determinación a obrar que surge de este perfeccionismo es, precisamente, el deseo. La virtud primaria que produce es el famoso conatus spinociano, perfil de su antropología y su moral: el esfuerzo por conservarse, la perseverancia en el ser, el deseo de eternidad (Ética, IV, XXIII).

Eje situado entre la plenitud y la eternidad, el desco es deseo omnívoro, de todo y para siempre. Cierta moral del barroco, encarnada en personajes míticos de la época (Don Juan Tenorio, el Doctor Fausto) pone en escena tal expansividad ética, que lleva al hombre a identificarse con Dios y con la naturaleza (que son lo mismo, en Spinoza) en una totalidad que se sitúa más allả de cualquier distinción, es decir, más allá de toda moral.

Apunto, para cerrar este apartado, una posible meditación barroca sobre el amor. En Descartes es «una emoción del alma causada por el movimiento de los espiritus, que la incita a unirse vohuntariamente a los objetos que parecen serle convenientes». Objeto conveniente, convenido, contratado: la declaración de amor. Hasta aquí, Descartes no se aparta de lo que sobre el amor dijeron Aristóteles y Santo Tomás: fusión de dos voluntades. Pero Cartesio añade un matiz que lo aparta de 
esta tradición escolástica: el objeto amoroso puede no ser voluntario, en cuyo caso el amor se define como un movimiento con o sin correspondencia. Sc abre el espacio del amor moderno, amor unilateral del amante, que nunca sabrá, en su fantástica desdicha, si el amado lo ama. Ni te importa gran cosa. Descartes anticipa a Werther, a los enamorados románticos, a los celosos proustianos. De hecho, Descartes cree que el amor a las cosas buenas y a las cosas bellas (agrado) sólo se cumple en los poemas y en las novelas. En la vida cotidiana, hay amistad por los iguales o devoción por los superiores. En cualquier caso, lejos de la cegucra convencional, el amor es lúcido. En efecto, si algo hace, es distinguir un objeto en medio del universo de los objetos. Spinoza, como siempre, irá más lejos: el amor es el sentimiento intelectual que tiene Dios, o sea la naturaleza, por sí mismo, y que cada uno de nosotros sentimos en nuestra medida. Es decir: nos queremos como dioses y nos amamos como totalidad. Lo que anticipa Spinoza, recayendo en la vieja categoría griega del eros, es cl crotismo modemo, ligado a la fantasía de eterna totalidad o a su destracción en el tânatos, que es el logro de una totalidad (negativa) eterna en su ausencia.

\section{II}

Según vamos viendo, el sentimiento moral y la formación de un posible sistema ćtico vienen y van a lo que podríamos llamar naturaleza ética del hombre, y no de su educación moral ni de su contacto con ninguna especie de revelación. Esto diseña una separación barroca entre religión y moral. Descartes se aparta de la tradición escolástica con su proyecto de filosofía natural, y Spinoza intenta componer el rompecabezas ético-pasional de la humanidad, acudiendo a una clave geométrica.

La naturaleza ética del hombre tiene un síntoma característico, que es la autoes- tima. El hombre autorreconoce lo bueno de su pasión y la encauza dentro del saber que la propia pasión le sugiere. Igualmentc, se autorrcconoce autor de un acto bueno o malo. El mérito personal es producto del autodominio. No es la aprobación ni el perdón de Dios, ni la gloria concedida pot los otros. Es la naturaleza ética que se producc y sc sabc. Tampoco sc trata de poner en juego una calidad genética (los valores nobles del aristócrata). O sea que la moralidad no es concesión de la sangre ni de la Gracia, sino obra práctica. Diríamos que el hombre es ético en potencia y que llega a ser moral en acto.

Algo similar podria decirse sobre el Dios de estos pensadores barrocos. Para Descartes, el hombre reconoce a Dios en su obra, que es el hombre mismo, con la ínsita idea de Dios que lleva como marca de fábrica. Para Spinoza, en tanto somos naturaleza y Dios lo es, todos somos un poco $\hat{E}$, que se ama intelectual o infinitamente en $E$ l, en la naturaleza y en nosotros (Ética, V, XXXV). En ambas propuestas, Dios no se revela ni se manifiesta, sino que está presente y oculto, a la vez, en la naturaleza de su creación y en su autocreación proliferante e infinita.

En este punto situamos una encrucijada fuerte de la ética barroca, que es la libertad como indeterminación. En las vacilaciones de Descartes respecto al tema (ver, por ejemplo, la carta al padre Mesland del 9 de febrero de 1645) se advierte lo dramático del asunto, ya que se trata de desviarse tanto de la tradición tomista, según la cual no hay libertad sino para hacer el bien, ya que nada ocurre en el universo que no sea querido por Díos y Él sólo quiere lo bueno, como también de la tradición agustiniana, es decir, la libertad como Gracia divina, amable pero misteriosa.

Si la libertad es prescindencia de códigos y tradiciones que nos detcrminan, es también voluntad autofundada. Para ello, hace falta un punto de partida radical: la indiferencia ante todo lo dado. Es así que 
el hombre es libre en tanto espontáneo, indeterminado y, por ello, no sólo es libre de hacer el bien, sino de hacer el mal. $Y$ responde ante su propia consciencia moral, y no ante un código legitimado por su autor. En este sentido, la libertad humana es absoluta y, por ello, trágica: entre Dios como causa principal y única, y el hombre como libre querer autofundado e indeterminado, hay un vinculo verdadero e irra zonable.

La respuesta diferida a Descartes es la de Spinoza: «Los hombres se creen libres porque no son conscientes de sus acciones e ignoran las causas que las determinan," Cabe traducir: el hombre se cree libre pero no lo es. Sólo la razón, que permite investigar las causas de la conducta humana, puede adquirir la libertad. Entonces, el hombre puede actuar de modo no causal. La libertad no es espontaneidad original, sino adquisición racional. Pero Spinoza y Descartes convergen en la fórmula barroca: libertad es indetcrminación.

Una posible síntesis de ambos senderos divergentes que sc encuentran donde el punto de partida de uno es el punto de llegada del otro, la hallamos en el teatro de Calderón (aclaro que cada vez que menciono el teatro de Calderón me refiero a su producción mayoritaria, dramas y comedias, y no a sus autos sacramentales, que ocupan no más de un tercio de su obra). La pregunta crucial acerca de la libertad es alli: ies libre el hombre ante una Providencia que todo lo sabe, puede, prevé y provee? La respuesta es: si, el hombre es librc en la medida en que puede descifrar el sitio que la Providencia le ha asignado en el orden del mundo. Las pistas para tal desciframiento están borradas y el hombre debe reconstruirlas guiándose por su instinto moral, que tiene tanto de la espontaneidad cartesiana como del razonamiento spinociano. El hombre no es libre porque se le imponga el código del bien revelado ni porque a Dios le da la gana, sino porque es capaz de razonar su deseo, conclusión a la que llegan esos dos egresados de los jesuitas que son Descartes y Calderón.

\section{III}

Si se quiere, estos vaivenes traducen la crisis religiosa y política del siglo xvII: guerras de religión, busca de una salida intelectual a la confrontación entre sistemas religiosos incompatibles, desplazamiento de la aristocracia territorial por la nobleza de toga, contrarreforma como reforma interna de Ia Iglesia, etc. Para los aficionados al almanaque: el Tratado de las pasiones se escribe a la vez que el Tratado de Westfalia, que acaba con la Guerra de los Treinta Años (1648).

Dentro de lo que nos interesa, señalo algunos indicios. La religiosidad barroca tiende a ser extraña a las instituciones, más interior: una espiritualidad que propende al abandono y la pasividad, contrarios al compromiso político de la Iglesia. En sus expresiones extremas: el galicanismo, el quietismo. Los fieles se organizan en pequeños grupos privados. Se tiende a la ceremonia secreta y a la reverencia por lo oculto. Si Dios existe, es un dieu caché, como San Pablo propone a Pascal. En Occidente, barrocamente, Dios se disimula como el sol tras el ocaso. El escepticismo ilustrado reemplazará a esta esquiva divinidad por una divinidad manifiesta, la Razón Universal. Y saldrán las Luces a iluminarlo todo.

Apartadas de esta religiosidad privada, las masas se entregan a la brujería y a la magia, formas de paliar la ausencia de Dios. En cualquier caso, se busca una religión natural, no dogmática, ni tampoco impuesta por el Estado como instrumento de dominación. Una moral sin religión aparece en el movimiento de los libertins (lo que hoy llamariamos librepensadores). Individual y privada, la moral barroca tien- 
de a exaltar al héroe, al único, al excepcional.

En otro orden, el metafísico, la crisis del Xvi empuja a revisar las nociones tradicionales de la Gracia y la Realidad. Francisco Suárez, jesuita él, por ejemplo, inventa una categoria media entre la Gracia divina y el mérito humano, la gratia congrua, Gracia previsora pero que premia las buenas acciones de los hombres. Lo mismo en cuanto a conciliar el nominalismo moderno (la autonomía del logos, a la cual aludimos al cmpezar estas páginas) y el realismo escolástico. Descartes acepta y rechaza las categorías de la Escuela. Caldcrón, formado en el tomismo, leerá tardiamente a San Agustín y adoptará alguna idea platónica filtrada por el obispo de Hipona: la belleza como forma sensible del bien, por ejemplo. También, cierta actítud estoica cristiana: la consideración de la muerte como fuente de la indiferencia que conduce a la libertad.

El teatro adquiere una importancia singular en este contexto. No sólo por la obvia teatralidad de la cultura barroca en general, sino porque en el teatro aparece el hombre como victima de sus pasiones, luchando contra ellas o afirmándose en ellas, para lograr su libertad. Los personajes del barroco son hijos abandonados que no pueden acudir a sus padres para que los auxilien en su enfrentamiento personal con el destino y consigo mismos. No es, entonces, gratuita la oposición de la Iglesia al teatro, las intermitentes clausuras de los espectáculos, y la sustitución del drama por el auto sacramental, donde no hay personajes, sino abstracciones cuyos enfrentamientos verbales están resueltos de antemano con recetas extraídas del dogma.

En el pequeño espacio que nos reúne, este teatro privado de las pasiones y la moral, la parábola barroca va de la admiración al utilitarismo. La admiración es el sentimiento barroco por excelencia: es lo que sentimos ante algo que creemos nuevo o nunca visto. Admiramos (nos detenemos a mirar, salimos de la inatención cotidiana $y$ sus fruiciones desatentas) lo raro 0 extraordinario: el monstruo barroco, un ser sin género, individuo o singularidad absoluta, lo maravilloso. Las sustancias de Spinoza y las mónadas de Leibniz son su formulación metafísica.

El monstruo barroco, la maravilla que es el objeto del arte, según Marino, es también emblema de la libertad como indeterminación, ya que al carecer de género, no ha de obedecer a ninguna característica genérica, a ninguna causa formal ni sustancial. Quede subrayado que, en la retórica batroca, monstruo no es palabra con connotaciones peyorativas, éticas ni estéticas. Se puede ser un monstruo de fealdad o de belleza, de maldad o de fidelidad, etcétera.

La admiración es considerada por Descartes como la primera pasión del alma, pero el filósofo nos previene contra ella, ya que es ciega. Si discierne su objeto como bueno, entonces se convierte en amor. Lo admirable puede ser dañino, lo amable es siempre benefico.

Lo contrario de la admiración es la utilidad spinociana, con la cual salimos de to maravilloso barroco hacia lo utilitario ilustrado. La virtud que nace del conatus se articula, para Spinoza, en un obrar y vivir conservando su ser, bajo la guía de la razón y buscando la propia utilidad. Esto es así hasta que aparece otro que opina 10 mismo, y que también quiere ser perfecto y etemo. Entonces, se pacta y se establece una tabla de castigos para quien exceda la medida socialmente útil. No se hace el mal por temor al castigo y el delito queda fuera del dominio del alma y de la moral. La razón, si acaso, hace que el hombre, cada hombre, desee para los demás el bien que desea para sí mismo, el cual deja de ser individual y privado, y se convierte en público y universal. La admiración por lo único, que está al comienzo de la construcción ético-pasional del barroco, se con- 
vierte en la virtud general y social de la conveniencia, el pacto y el código de premios y castigos. Pero queda la gran fantasía de la razón como legisladora universal: que lo bucno para cada cual sea bueno para todos.

\section{IV}

Con algunos ejemplos literarios de la época puede cerrarse el esbozo anterior. Ante todo, en dos mitos que aparecen en el barroco y que merecerấn una descendencia complicada y equivoca: Don Juan (Tirso de Molina o quien fuere, Molière) y Fausto (Christopher Marlowe). En ambos, el yo, sujeto y agente del deseo y del conato (apetencia de mundo como objetalidad, saber del mundo), es afirmación absoluta. Lo que se sitúa fuera del yo es motivo de apetencia, cosa apetecible. Las mujeres, la ciencia, el poder, la inmortalidad de una juventud perpetuamente recuperable. El hombre es imagen de ese Dios que se confunde con la Naturaleza y aparece, por ello, en el fondo de la naturaleza humana. Omnipotente y único, el individuo se torna universo. Lo cargan estas potencias de organización, creativas, pero también las tendencias egocéntricas y anárquicas, las fuerzas que dinamizan y destruyen.

El tema de la naturaleza como sede de la vida moral, o del naturalismo ético, se desplega en Cervantes, según lo que concluyc Amćrico Castro en El pensamiento de Cervantes, a cuya lectura me remito. Más aún: hay un fondo común religioso a todos los hombres, donde las diversas personificaciones de lo divino y lo santo se reưnen en una suerte de sincretismo. Así lo ejemplifica el personaje cervantino conocido como la hija de Agí Morato, que aparece en las comedias La gran sultana y Los baños de Angel, y en el episodio del cautivo del Quijote (I, XXXIX y ss.). Me permito remitir a mi trabajo «Cervantes et lc Maghreb» (cn prensa: Littératures frontalieres, Bulzoni, Roma).

En el doble sentido de la palabra, aparece la naturaleza en el shakespeariano Hamlet (las citas textuales están tomadas de la traducción de Astrana Marín). La naturaleza, por una parte, es el origen, aquello de nosotros que no hemos elegido. Hamlet se considera eun juguete de la naturaleza». Es la naturaleza en tanto sencillez primitiva que el mismo Hamlet invoca como calidad del arte dramático (incumplido por Shakespeare, como es sabido). Esta naturaleza es lo opuesto a la costumbre, lo extraordinario o monstruoso que irrumpe en el curso de lo esperable, de lo posible.

En otro sentido, la naturaleza es el lugar y el proceso de la moralidad humana. Dice Laertes a Ofelia: «... la Naturaleza, al hacernos crecer, no sólo nos favorece en fuerzas y volumen, sino que a medida que va ensanchando el templo, dilata con él, a la par, el espacio interno de inteligencia y almà, A su vez, Ofelia, admitiendo la aparición de esta «segunda» Naturaleza, reflexiona: «Debo ser cruel, pero no convertirme en desnaturalizada.»

El arte, dentro de esta dialéctica de la doble naturaleza, cumple una misión restauradora moral: poner de manifiesto, "inaturalmente», el delito oculto por la costumbre (Hamlet: aLos actos criminales surgirán a la vista de los hombres, aunque los sepulte toda la tierras). Por eso, Hamlet, loco fingido, sólo habla seriamente con los cómicos Rosenkrantz y Guildestern, así como el rey Lear sólo habla seriamente con el bufón. La comedia montada por Hamlet hace aflorar la naturaleza moral de los criminales, la madre y su amante. Curiosamente, el crimen del rey ilegítimo es, más que haber matado a su hermano, no poder arrepentirse de haberlo hecho.

¿Por qué se sitúa en el arte, en la comedia que sirve de catarsis a los delincuentes, la naturaleza moral, a la vez originaria y final, del hombre? La respuesta puede ser: 
porque la moral es algo utópico, un mundo que cntrevemos cuando el arte nos lo representa, pero que no integra nuestra vida efectiva. Porque, como dice Ofelia, «sabemos lo que somos, más no lo que podemos ser». El mismo Hamlet, que se propone como justiciero, en rigor no quiere hacer justicia, sino vengarse.

En el delirio de su libertad, Hamlet se finge loco y denuncia lo convencional de los roles sociales, que equivalen a los disfraces de una comedia. La locura del mundo, tópico barroco, señala al gran teatro del mundo, tópico barroco. En algún lugar, sin embargo, debe estar la cordura que nos permite distinguir la locura, y la realidad que nos permite distinguir la ficción. De nuevo, es el arte el que provee de tales categorías, el arte como ensueño de la razón.

La conclusión shakespeariana es trágica. No sólo porque Hamlet es instrumento de la pasión, como su madre y su tío, sino porque su fingida locura, que le permite liberarse de toda convención y alcanzar la libertad de lo indeterminado, lo conduce asimismo al descontrol de sus pasiones y a la anulación de su identidad, proceso simbolizado por el fantasma del padre. Hamlet no puede inhumar a su padre muerto ni, por lo tanto, ocupar su lugar. El padre sigue reapareciendo, como si ignorase que está muerto, y a tener, la apariencia corporal de un vivo. Hamlet es un buen instrumento, pero del cual nadie puede extraer ningún sonido (buena definición de la psicosis). Ni siquiera el sonido del nombre propio, pues Hamlet se llama como su padre. Cuando se habla del fantasma de Hamlet, se habla, justamente, del fantasma de Hamlet.

Vale la pena retener este concetto barroco: para denunciar la locura del mundo, aparecen tres locos fingidos de notable calidad: Don Quijote, Hamlet, el rey Lear. $\mathrm{Y}$ así como cl conflicto de dos naturalezas igualmente ilegítimas resulta trágico, tam- bién acaba siêndolo el conflicto entre estas dos locuras «legitimas».

Algo similar ocurre en la Fedra de Racine. Fedra se enamora de su hijastro Hipólito en ausencia del marido Teseo. Pero, en realidad, no es Fedra quien se enamora, sino la diosa Venus quien la posee, la otredad de la pasión. Incestuosa y adúltera, su falta de razón consiste, justamente, en no ser ella misma, o sea un instrumento de su razón y una correcta reina, esposa y madrastra, ya que la razón es el principio ordenador del mundo a través de las identidades sociales. Fedra es una posesa de Venus, un ser inhumano y divino. Por eso, Enona, su criada, representante de la moral fáustica barroca, sostiene su inocencia, pues no es Fedra quien ha faltado a la ley, sino la fatalidad misma, personificada en una divinidad.

Ahora bien, el resto de los personajes, aunque invocando propósitos inmejorables, tampoco es un ejemplo de racionalidad. Es cierto que Fedra propone un embrollo inmoral fuerte (se deja enamorar por su hijastro, lo acusa falsamente ante su marido, quiere cargarse a Aricia, que se ama con Hipólito), pero Teseo, que representa la autoridad de la razón, es llevado por una injusta ira, y el pobre Hipólito sc permite amar a Aricia, mujer que le prohíbe la ley de sus mayores. Fedra sólo recupera la razón al morir ante su esposo, confesando todas sus faltas. $O$ sea: aqui nadie hace lo que debe y el valor ético de la pasiones consiste en mover al sujeto a gobernarlas, cosa que sólo ocurre en el arte, que muestra cómo somos víctimas de nuestras pasiones, que nos convierten en dioses, con funestos efectos. La moraleja es que el hombre debe ser humano y encajar en la geometría social de la ley, o alcanzar la divina locura de la pasión. Es decir: la antigua fatalidad pagana, revista por la responsabilidad individual del cristianismo, que considera trágica una vida moral dominada por la pasión, a la vez que ejemplar la obra de arte que exhibe este trágico 
escenario. Las fuerzas trágicas, que en el mundo clásico son exteriores al sujeto, espacio vacío, se internalizan en Racine, pues el suyo es un individuo dotado, precisamente, de alma individual. Surgen tales fuerzas del interior anímico y se proyectan sobre el mundo. Responsable de su fatalidad pasional, el héroe raciniano, como observa Bénichou, se encamina hacia la angustia del remordimiento y el autodesprecio. Ya no es la víctima de su sino grandioso ni se enfrenta a la hostilidad de los dioses; se muestra, más modestamente, incapaz de gobernar sus impulsos. Disgustado por su naturaleza, siente malestar por su condición y vuelva su pesimismo ético en la tragedia raciniana: el mouvement que conduce al malaise. Su utopia moral puede ser la propuesta por Gracián (Oráculo manual y arte de pridencia, VIII): «Hombre inapasionable, prenda de la mayor alteza de ánimo." La utopía moral kantiana, de un sujeto que sólo se determina, con ánimo alto, por pautas racionales.

Vamos a terminar con Calderón, que nos propone un final feliz. Salgamos de la tragedia, que es el conflicto entre dos legalidades igualmente válidas, y vayamos al drama, que es el conflicto entre la única ley legítima (valga la redundancia) y una percepción equivocada de la misma.

En La vida es sueño (el drama, no el auto sacramental) tenemos al típico personaje barroco, arrojado a un mundo extraño, ignorante de su origen y sin referencias identificatorias. Segismundo, criado en una prisión, sólo ve a un semejante, Clotaldo, que es su carcelero, quien siempre se le aparece barrocamente enmascarado. Su naturaleza moral le enseña, observando la «política» (sic) de los animales, que no es como ellos, que la libertad existe y él no la goza, y que hereda el pecado original, el mayor pecado: haber nacido.

Basilio, el rey, su padre, cree en la astrología, como tantos poderosos de su tiempo (ver Gracián, op. cit., CXCVI, «Conocer su estrellas) $y$, por temor a un vaticinio adverso, priva a su hijo de historia, o sea de identidad. El problema de Segismundo será llegar a su reconocimiento y a la constitución de su sentimiento y su código moral, a partir de sí mismo, en medio de lo que define Glotaldo: «Es todo el ciclo un presagio/ $y$ es todo el mundo un prodigio." La maestra de Segismundo es la que señala el mismo personaje: «... las letras/ humanas que le ha enseñado/ la muda naturaleza/ de los montes y los cielos/ en cuya divina escuela/ la retórica aprendió/ de las aves y las fieras».

Puesto en libertad, Segismundo se porta de modo criminal: mata a un criado, está por violar a Rosaura, amenaza de muerte a Clotaldo. Devuelto a la prisión, cree haber soñado y pone en duda, cartesianamente, la calidad real del mundo, salvo su amor por una mujer. Éste puede ser el punto de vigilia que permita considerar que la vida es sueño. Como Hamlet, Segismundo cree que estamos hechos de la materia/madera de los sueños y que nuestras identidades son convencionalismos teatrales. Pero nada de ello impide que su naturaleza moral, en contacto con la pasión y la otredad, se proponga como real. El bicn es la realidad. «Quc cstoy soñando y que quiero/obrar bien, pues no se pierde/ obrar bien, ni aun entre sueños.»

Rosaura, el otro, ese personaje que puede emblematizar a la humanidad, y que aparece vestida de mujer o de varón, cuando es capaz de contar su propia historia a Segismundo (la historia de él), como si fuera su madre-padre, consigue dotarlo de realidad, de una realidad que el mismo Segismundo acaba por admitir como tal. Cuando alguien lo interpela, no sueña. El ser le viene del otro, en tanto él lo acepte como tal otro. Gozo real del momento presente, vivido entre dos suenos: la vida.

Dije que el final era feliz. Efectivamente, por sus buenas acciones guerreras y políticas, Segismundo termina reconocido por su padre Basilio, que advierte su calidad moral, preescrita en las estrellas por 
la mano de Dios. Se asegura la continuidad dinástica y la «alteza de ánimo» del príncipe.

Desde una armonía perdida a una armonía recuperada, el drama calderoniano traza la parábola de la instauración de la ley sin que medie ninguna revelación, educación ética, tarea sacerdotal ni institución cclesial alguna. Cuenta el nacimiento de una culpabilidad difusa (cf. Souiller) que surge de la percepción del otro. El sujeto se constituye a partir de esta escena y la eleva a legalidad al componerla con la kgallarda máquina» del universo. Sólo este proceso rescata al hombre, de suyo miserable y absurdo, y lo sustrae al aniquilamiento de una apasionada inmersión en lo inmediato. Tampoco es Dios el que dota de realidad al hombre, dispensándole su Gracia. Dios ha instaurado la ley, la ha disimulado en sus signos atesorados por la naturaleza, y se ha retirado a un punto de infinita distancia, que equivale a su ausencia. Su creación, gratuita y angustiosa para el hombre abandonado en ella a sus propias fuerzas, convoca la incertidumbre y el miedo al sinsentido. Pero siempre hay recursos para despertar del sueño de la vida. Por ejemplo, que alguien nos diga: tú.

\section{BIBLIOGRAFÍA}

BÉnichou, Paul: Morales du grand siècle, Gallimard, París, 1948, cap. «Racine». BODEr, Remo: Una geometría de las pasiones. Miedo, esperanza y felicidad: filosofía y uso político, trad. de José Ramón Monreal, Muchnik, Barcelona, 1995.

Certeau, Michel de: La escritura de la historia, trad. de Jorge Lopez Moctezuma, Universidad Iberoamericana, México, 1993, cap. «Producción del tiempo. Una arqueología religiosas.

DEscartes: Oeuvres philosophiques, III (1643-1650), ed. Fernand Alquié, Bordas-Garnier, París, 1989.

Sounller, Didier: Calderón ou le grand théatre du monde, PUF, París, 1992. SPINOZA: Ética demostrada según el orden geométrico, trad. de Óscar Cohan, FCE, México, 1958. 